\title{
Effect of Processing on Microstructure and Corrosion Mitigating Properties of Hydrotalcite Coatings on AA 6061 Alloy
}

\author{
Stela Maria de Carvalho Fernandes ${ }^{a}$, Olandir Vercino Correa ${ }^{a}$, José Antonio Batista de Souza ${ }^{a}$,
} Renato Altobelli Antunes ${ }^{b}$, Nelson Batista de Lima ${ }^{a}$, Lalgudi Venkataraman Ramanathan ${ }^{a *}$

${ }^{a}$ Comissão Nacional de Energia Nuclear, Instituto de Pesquisas Energéticas e Nucleares - IPEN, Av. Professor Lineu Prestes, 2242, CEP 05508-000, São Paulo, SP, Brazil

${ }^{b}$ Centro de Engenharia, Modelagem e Ciências Sociais, Universidade Federal do ABC-UFABC, CEP 09210-170, Santo André, SP, Brazil

Received: July 13, 2015; Revised: September 21, 2015

\begin{abstract}
Pitting corrosion of the aluminium cladding of spent nuclear fuels stored in light water pools has been observed. To prevent this, coating of the Al cladding with hydrotalcite (HTC) was proposed. This paper presents the effect of chemical bath and processing parameters on microstructure and corrosion behavior of HTC coatings on alloy AA 6061 specimens. The HTC coating from the high temperature nitrate bath was homogeneous, thicker and consisted of well-defined intersecting platelets than that formed from the room temperature carbonate bath. Electrochemical polarization tests carried out with HTC coated AA 6061 specimens in $0.01 \mathrm{M} \mathrm{NaCl}$ revealed that specimens coated with HTC from the nitrate bath and further treated in a cerium salt solution were the most resistant to corrosion. Field tests in which un-coated and coated AA 6061 alloy coupons as well as full-size plates were exposed to the IEA-R1 reactor's spent fuel basin for duration of up to 14 months further corroborated the high corrosion resistance imparted by the high temperature HTC $+\mathrm{Ce}$ coating. The mechanism by which the HTC coating and cerium protect the $\mathrm{Al}$ alloy is discussed.
\end{abstract}

Keywords: hydrotalcite, coatings, corrosion, aluminum alloy

\section{Introduction}

In most countries spent aluminum-clad nuclear fuels from research reactors (RRs) are stored for decades in light water pools or basins. Despite water quality management programs at the fuel storage sites, pitting corrosion has been reported. This is the main form of degradation that could lead to cladding breach, release of fissile material and radioactive contamination of the storage facilities ${ }^{1}$. Pitting corrosion of the fuel cladding has been attributed to synergism in the effect of some basin water parameters on corrosion of aluminum and its alloys ${ }^{1,2}$. Hence, it was imperative that some form of corrosion protection be given to the Al cladding of spent RR fuel. A RR fuel, also referred to as a fuel element, consists of an assembly of 18 or more Al-clad fuel plates. The complex shape of the fuel element and high radioactivity of spent fuels preclude electrochemical surface treatments. Therefore chemical surface treatment to form a coating is the only option. Conversion coatings (CC) have been widely used in many industries to control the corrosion of a variety of metals. A chromium based CC is considered a near ideal coating for many metals. However, chromates being carcinogenic and a toxic substance are being progressively phased out. A significant amount of data is available on potential chromate replacements for Al alloys. These include molybdates, permanganates, phosphates, refractory metal oxyflourides, silanes, sol-gels,

*e-mail: lalgudi@ipen.br self assembling monolayers, conductive polymers, cobalt based coatings, hydrotalcites and rare earths ${ }^{3}$.

It is well known that in alkaline solutions $\mathrm{Al}$ exhibits a high dissolution rate, but surprisingly when $\mathrm{Al}$ is immersed in an alkaline lithium salt solution it forms a continuous surface film which confers passivity. The composition of this film has been reported to be predominantly $\mathrm{La}_{2}\left[\mathrm{Al}_{2}(\mathrm{OH})_{6}\right]_{2} \cdot \mathrm{CO}_{3} \cdot \mathrm{nH}_{2} \mathrm{O}$ (lithium aluminum hydroxide-carbonate (or nitrate)-hydrate), that belongs to the hydrotalcite mineral family, a form of 'talc'4-6. Hence, hydrotalcite (HTC) was considered to protect the aluminum cladding of spent nuclear fuel.

This paper presents the preparation of HTC coatings on aluminum alloy AA 6061 specimens and the effect of bath composition, temperature and duration of treatment on the microstructure of the coating as well as on the corrosion behavior of uncoated and HTC coated Al alloy specimens. Rare earth compounds have been used as corrosion inhibitors of aluminum alloys ${ }^{7-10}$. Preliminary investigations revealed that chemical treatments to form lanthanide based coatings on $\mathrm{Al}$ alloys AA 1100 and $\mathrm{AA} 6061$ increased the corrosion resistance of the alloys ${ }^{11-13}$. Hence, the effect of cerium incorporation in the HTC coating on corrosion behavior of AA 6061 alloy was also studied. Further, field tests were carried out in which, un-coated and coated Al alloy coupons as well as full-size plates were exposed to a spent fuel basin for periods of up to 14 months and then examined. 


\section{Methods and Material}

Aluminium alloy AA 6061-T6 $(0.94 \mathrm{Mg}, 0.65 \mathrm{Si}, 0.25 \mathrm{Cu}$, $0.24 \mathrm{Fe}$, balance $\mathrm{Al}$ ) is the cladding material of most research reactor fuels and was therefore used in this investigation to prepare laboratory test specimens and field test coupons as well as plates. Different alkaline lithium salt solutions have been used to form HTC on a variety of Al alloys at many temperatures ${ }^{4}$. Table 1 shows the different solutions and the conditions under which these solutions were used to coat and post-treat the specimens, coupons and plates. All the aluminium alloy specimens, coupons and plates were degreased and deoxidized prior to immersion in the lithium nitrate solution at $98^{\circ} \mathrm{C}$ (referred to as HT-HTC) or in the lithium carbonate solution at room temperature (referred to as LT-HTC). The procedure to prepare solution 1 and 2 of Table 1 consisted in adding $\mathrm{LiOH}$ to the $\mathrm{LiNO}_{3}$ or $\mathrm{Li}_{2} \mathrm{CO}_{3}$ solution to adjust the $\mathrm{pH}$ to 12 followed by dissolution of an AA 1100 sheet in this solution to obtain sufficient $\mathrm{Al}^{3+}$ ions in solution, essential to form $\mathrm{HTC}^{[4]}$. All the coated specimens, coupons and plates were rinsed in deionized water. Cerium was incorporated in the coating of some of the HT-HTC coated specimens, coupons and plates by immersion in solution 3 and in the coating of some of the LT-HTC coated specimens by immersion in solution 4 followed by rinsing in deionized water. This procedure to incorporate cerium in the HT-HTC from $\mathrm{CeCl}_{3}$ solution at $98{ }^{\circ} \mathrm{C}$ and in the LT-HTC from $\mathrm{Ce}\left(\mathrm{NO}_{3}\right)_{3}$ solution at RT was adopted to compare a high temperature process as opposed to a room temperature process. The latter is easier to scale-up to treat radioactive spent fuels.

$\mathrm{X}$-ray diffraction analysis of the coatings formed from solutions 1 and 2 of Table 1 was performed. The thickness of the coating formed from solution 1 was adequate to carry out grazing angle diffraction analysis. However, the thickness of the coating formed from solution 2 was insufficient for XRD analysis. Hence a powder sample of the Al alloy, with substantially increased surface area to volume ratio, was treated in solution 2 to form a sufficient amount of coating, and then analyzed in the diffractometer. The morphology of the coated specimens was examined using a Jeol FEG-SEM operated at $3 \mathrm{kV}$.

The electrochemical behavior of uncoated and coated specimens $20 \mathrm{~mm} \times 20 \mathrm{~mm}$ was determined in $0.01 \mathrm{M} \mathrm{NaCl}$ solution at room temperature. Anodic potentiodynamic polarization measurements were carried out with a standard 3-electrode arrangement consisting of a working electrode, a saturated calomel reference electrode and a platinum counter electrode. The potential was scanned from $-1.0 \mathrm{~V}$ to $+0.4 \mathrm{~V}$ at $0.1 \mathrm{mV} / \mathrm{s}$.

Field tests were carried out and this consisted of preparing uncoated and HTC coated AA 6061 alloy coupons $(10 \mathrm{~cm}$ in diameter and $3 \mathrm{~mm}$ thick $)$ and full-size plates $(62.5 \mathrm{~cm} \times 7.0 \mathrm{~cm}$ to resemble fuel plates). The coupons were assembled in racks and the plates were assembled to form dummy fuel elements ${ }^{1}$. Preparation of HTC coated coupons and plates was done using the solutions and conditions shown in Table 1. The racks and dummy elements were placed in the spent fuel section of the IEA-R1 research reactor in IPEN, Brazil, for periods of up to 5 and 14 months respectively and then withdrawn. These withdrawn racks and dummy fuels were
Table 1. Solutions and conditions used to prepare and treat coatings on AA $6061^{[14]}$

\begin{tabular}{|c|c|c|}
\hline Solution & Purpose & $\begin{array}{c}\text { Composition of solution and } \\
\text { conditions }\end{array}$ \\
\hline 1 & $\begin{array}{c}\text { Form } \\
\text { HT-HTC }\end{array}$ & $\begin{array}{l}6.9 \mathrm{~g} / \mathrm{L} \mathrm{LiNO}_{3} ; 28.3 \mathrm{~g} / \mathrm{L} \mathrm{KNO}_{3} \\
2.4 \mathrm{~g} / \mathrm{L} \mathrm{LiOH} ; 0.06 \mathrm{~g} / \mathrm{L} \mathrm{NaAlO}_{2} \\
98{ }^{\circ} \mathrm{C} ; \mathrm{pH} 12 ; 10 \mathrm{~min} .\end{array}$ \\
\hline 2 & $\begin{array}{l}\text { Form } \\
\text { LT-HTC }\end{array}$ & $\begin{array}{c}\text { 0.1 } \mathrm{M} \mathrm{Li}_{2} \mathrm{CO}_{3} ; \mathrm{LiOH} ; \mathrm{Al} ; \mathrm{pH} 12 ; \\
15 \text { min; R.T. }\end{array}$ \\
\hline 3 & $\begin{array}{l}\text { Incorporate } \\
\mathrm{Ce}\end{array}$ & $0.1 \% \mathrm{CeCl}_{3} ; 97^{\circ} \mathrm{C} ; \mathrm{pH} 4 ; 5 \mathrm{~min}$. \\
\hline 4 & $\begin{array}{l}\text { Incorporate } \\
\mathrm{Ce}\end{array}$ & $\begin{array}{c}10 \mathrm{~g} / \mathrm{L} \mathrm{Ce}\left(\mathrm{NO}_{3}\right)_{3 ;} 30 \% \mathrm{H}_{2} \mathrm{O}_{2} ; \mathrm{R} . \mathrm{T} \text {; } \\
5 \mathrm{~min} .\end{array}$ \\
\hline
\end{tabular}

Table 2. Effect of HTC coating on corrosion potential $\left(\mathrm{E}_{\text {corr }}\right)$ and corrosion current density $\left(i_{\text {corr }}\right)$ of AA 6061 in $0.01 \mathrm{M} \mathrm{NaCl}$.

\begin{tabular}{ccc}
\hline $\begin{array}{c}\text { Specimen } \\
\text { condition }\end{array}$ & $\mathbf{E}_{\text {corr }}(\mathbf{V})$ & $\mathbf{i}_{\text {corr }}\left(\boldsymbol{\mu A . \mathbf { c m } ^ { - 2 } )}\right.$ \\
\hline Untreated & -0.79 & 1.56 \\
HT-HTC $\left(20^{\prime}\right)$ & -0.58 & 0.35 \\
LT-HTC $\left(20^{\prime}\right)$ & -0.59 & 0.77 \\
\hline
\end{tabular}

then rinsed, decontaminated, disassembled and the surfaces of the coupons/plates examined with an optical microscope.

\section{Results}

\subsection{Composition and microstructure of the coatings}

The x-ray diffraction spectra of the coatings on AA 6061 immersed in solution 1 at $98^{\circ} \mathrm{C}$ and in solution 2 at room temperature are shown in Figure 1. The spectra reveal HTC formation in both solutions. Some bayerite was also detected in the coating formed in solution 2 at room temperature. The amount of HTC formed was quite thin as only a few peaks corresponding to $\left(\mathrm{Li}_{2}\left[\mathrm{Al}_{2}(\mathrm{OH})_{6}\right]_{2} \mathrm{CO}_{3}\right.$ $\left.3 \mathrm{H}_{2} \mathrm{O}\right)$ are discernible. The HTC formed as a coating on the sheet specimen surface in solution 1 was thicker and easily identified from the JCPDS file.

The HTC coatings formed in solutions 1 and 2 were uniform and their morphologies are shown in Figure 2. The coating formed in both solutions consisted of intersecting blade-like crystallites. The HTC crystallites formed in solution 1 were larger and well defined compared with that formed in solution 2. The HTC coating also formed inside pits and recesses that were created during pre-treatment of the substrate as shown in Figure 3. Typical HT-HTC coating thickness after 10 minutes of immersion was $\sim 2 \mu \mathrm{m}$. A dense layer of amorphous or nanocrystalline HTC forms underneath the top layer as shown in Figure $4^{5,6}$. The coating thickness increased with duration of treatment in solutions 1 and 2, but no change in morphology was observed with duration of treatment.

\subsection{Electrochemical behavior}

The anodic polarization curves of uncoated and HTC coated AA 6061 specimens in $0.01 \mathrm{M} \mathrm{NaCl}$ are shown in Figure 5a. This figure reveals that coating of the specimen 

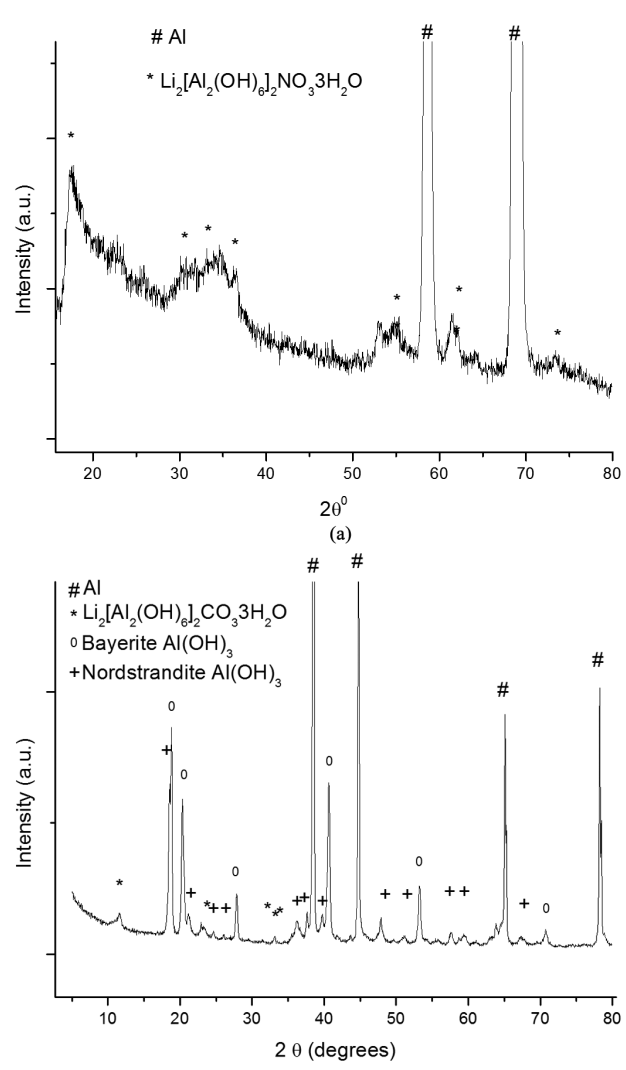

(b)

Figure 1. X-ray diffraction spectra revealing HTC formed on AA 6061 specimens in the: (a) nitrate bath at $98{ }^{\circ} \mathrm{C}(\mathrm{Cr}-\mathrm{K} \alpha)$; (b) carbonate bath at room temperature $(\mathrm{Cu}-\mathrm{K} \alpha)$.

increased its corrosion resistance in $\mathrm{NaCl}$ by increasing the corrosion potential $\left(\mathrm{E}_{\text {corr }}\right)$ and decreasing the corrosion current density $\left(i_{\text {corr }}\right)$. The latter was determined from the polarization curves by Tafel extrapolation. This figure also reveals that the $\mathrm{E}_{\text {corr }}$ of HT-HTC coated specimen is slightly higher than that of the specimen coated with LT-HTC. Figures $5 \mathrm{~b}$ and $5 \mathrm{c}$ show the polarization curves of specimens coated with HT-HTC and LT-HTC respectively for 20, 30 and 60 minutes. It is evident from these figures that coating thickness has no significant effect on the $\mathrm{E}_{\text {corr }}$. The anodic polarization curves of all the other coated specimens were similar to those shown in Figure 5. Data extracted from the polarization curves of the different specimens are summarized in 5 different tables (Tables 2-6) to facilitate comparisons and observe the effect of specific parameters.

Table 2 shows that either type of coating increases corrosion resistance of the $\mathrm{Al}$ alloy in $\mathrm{NaCl}$ solution. That is, $\mathrm{E}_{\text {corr }}$ increases and the $\mathrm{i}_{\text {corr }}$ decreases. The $\mathrm{i}_{\text {corr }}$ values of HT-HTC and LT-HTC coated specimens indicate that the latter is less protective. Table 3 shows that the $i_{\text {corr }}$ of specimens coated with HT-HTC for longer times increased with duration of treatment in the lithium nitrate solution. This increase in $i_{\text {corr }}$ is due to the HT-HTC coatings containing increasing amounts of co-deposited alloying and/or impurity elements that dissolved from the substrate, besides depletion of $\mathrm{Al}$ ions. The $\mathrm{i}_{\text {corr }}$ of specimens coated with LT-HTC for 20, 30 and $60 \mathrm{~min}$ did not vary significantly as shown in Table 4 . The reason being

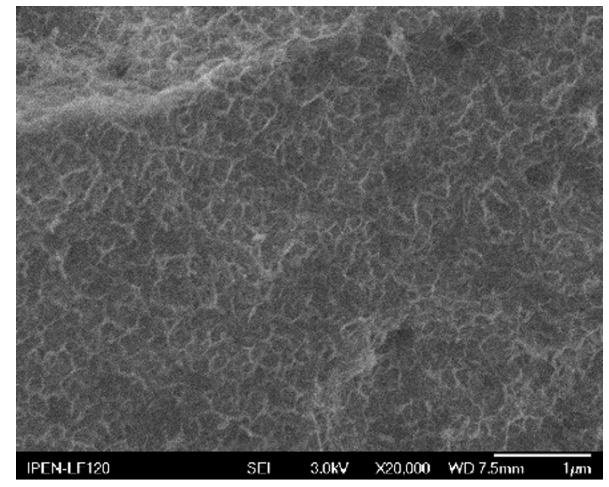

(a)

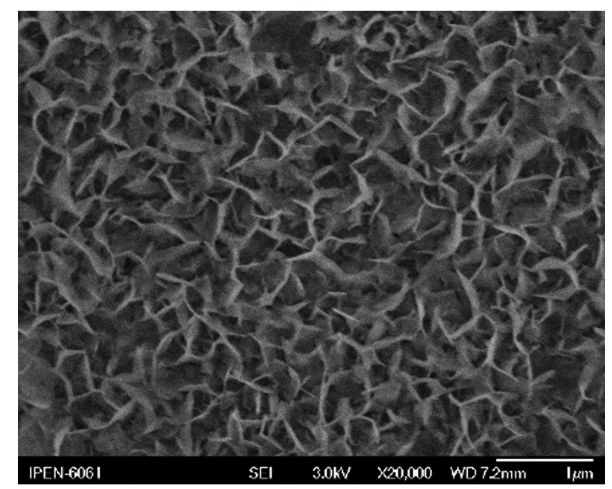

(b)

Figure 2. Scanning electron micrographs of: (a) LT-HTC (b) HT-HTC.

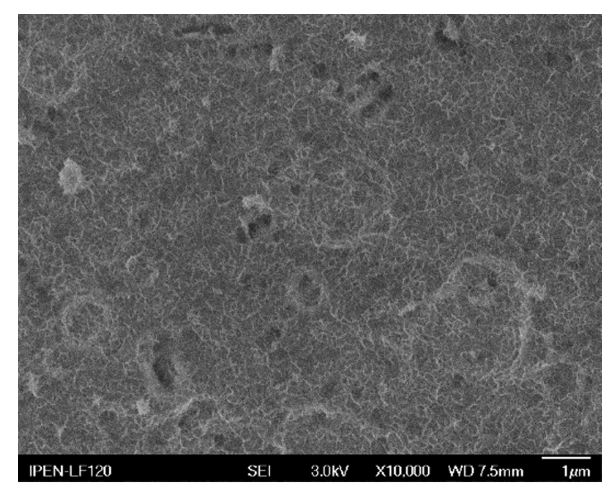

(a)

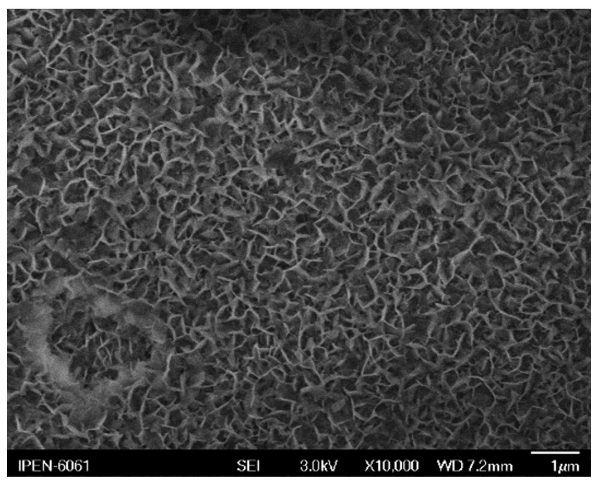

(b)

Figure 3. Scanning electron micrographs revealing HTC formation within pits and crevices: (a) LT-HTC; (b) HT-HTC. 


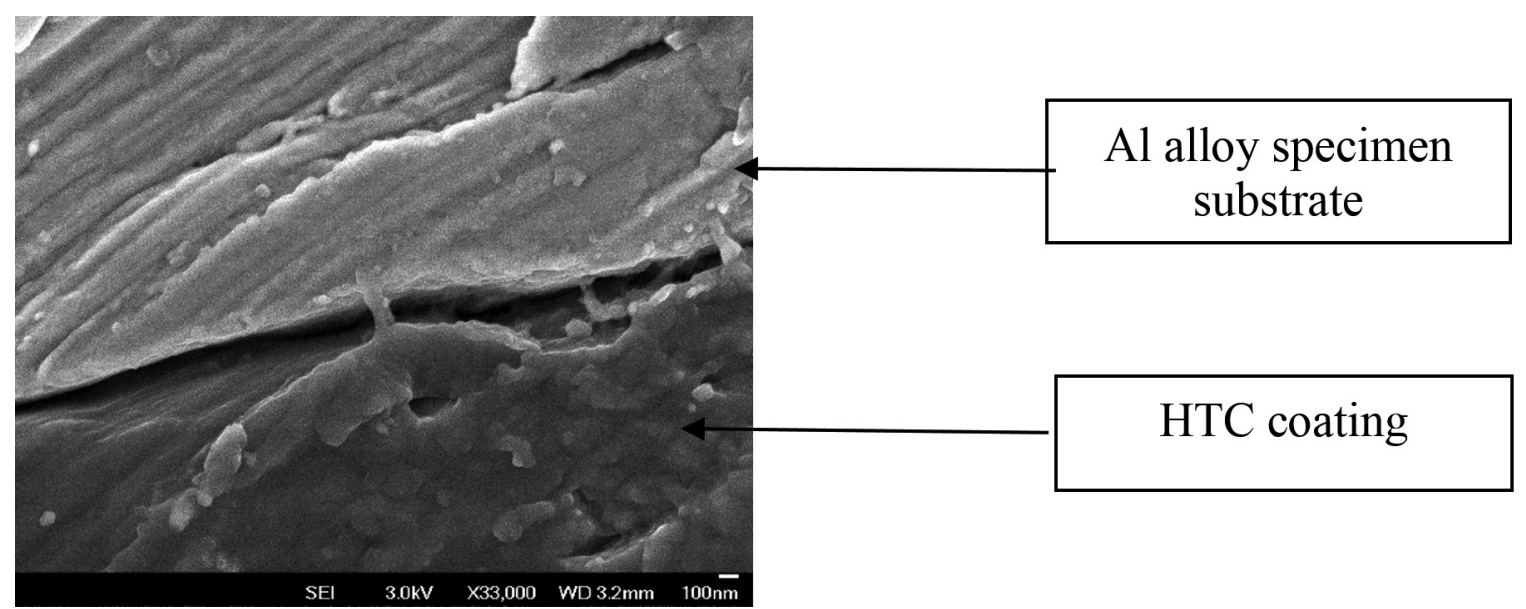

Figure 4. Scanning electron micrograph of cross section of HT-HTC coated specimen showing dense layer close to alloy.

Table 3. Effect of duration of HT-HTC formation on $\mathrm{E}_{\text {corr }}$ and $\mathrm{i}_{\text {corr }}$ of uncoated and coated AA 6061 in $0.01 \mathrm{M} \mathrm{NaCl}$.

\begin{tabular}{ccc}
\hline Specimen condition & $\mathbf{E}_{\text {corr }}(\mathbf{V})$ & $\mathbf{i}_{\text {corr }}\left(\boldsymbol{\mu A} \mathbf{A . c m}{ }^{-2}\right)$ \\
\hline Untreated & -0.79 & 1.56 \\
HT-HTC $\left(20^{\prime}\right)$ & -0.58 & 0.35 \\
HT-HTC $\left(30^{\prime}\right)$ & -0.57 & 0.78 \\
HT-HTC $\left(60^{\prime}\right)$ & -0.58 & 0.93 \\
\hline
\end{tabular}

Table 4. Effect of duration of LT-HTC formation on $\mathrm{E}_{\text {corr }}$ and $\mathrm{i}_{\text {corr }}$ of uncoated and coated AA 6061 in $0.01 \mathrm{M} \mathrm{NaCl}$.

\begin{tabular}{ccc}
\hline Specimen condition & $\mathbf{E}_{\text {corr }}(\mathbf{V})$ & $\mathbf{I}_{\text {corr }}\left(\boldsymbol{\mu} \mathbf{A . c m}{ }^{-2}\right)$ \\
\hline Untreated & -0.79 & 1.56 \\
LT-HTC $\left(20^{\prime}\right)$ & -0.59 & 0.77 \\
LT-HTC $\left(30^{\prime}\right)$ & -0.59 & 0.46 \\
LT-HTC $\left(60^{\prime}\right)$ & -0.60 & 0.72 \\
\hline
\end{tabular}

Table 5. Effect of duration of cerium treatment of HT-HTC coated AA 6061 specimens on $\mathrm{E}_{\text {corr }}$ and $\mathrm{i}_{\text {corr }}$ in $0.01 \mathrm{M} \mathrm{NaCl}$.

\begin{tabular}{lcc}
\hline \multicolumn{1}{c}{ Specimen condition } & $\mathbf{E}_{\text {corr }}(\mathbf{V})$ & $\mathbf{i}_{\text {corr }}\left(\boldsymbol{\mu A . . \mathbf { c m } ^ { - 2 } )}\right.$ \\
\hline HT-HTC $\left(20^{\prime}\right)$ & -0.58 & 0.35 \\
HT-HTC $\left(20^{\prime}\right)+\mathrm{Ce}\left(5^{\prime}\right)$ & -0.60 & 0.26 \\
HT-HTC $\left(20^{\prime}\right)+\mathrm{Ce}\left(10^{\prime}\right)$ & -0.59 & 0.12 \\
HT-HTC $\left(20^{\prime}\right)+\mathrm{Ce}\left(15^{\prime}\right)$ & -0.59 & 0.37 \\
\hline
\end{tabular}

Table 6. Effect of duration of cerium treatment of LT-HTC coated AA 6061 specimens on $\mathrm{E}_{\text {corr }}$ and $\mathrm{i}_{\text {corr }}$ in $0.01 \mathrm{M} \mathrm{NaCl}$.

\begin{tabular}{lll}
\hline \multicolumn{1}{c}{ Specimen condition } & \multicolumn{1}{c}{$\mathbf{E}_{\text {corr }}(\mathbf{V})$} & $\mathbf{i}_{\text {corr }}\left(\boldsymbol{\mu A} \mathbf{A . c m}{ }^{-2}\right)$ \\
\hline LT-HTC $\left(20^{\prime}\right)$ & -0.59 & 0.77 \\
LT-HTC $\left(20^{\prime}\right)+\mathrm{Ce}\left(5^{\prime}\right)$ & -0.58 & 0.96 \\
LT-HTC $\left(20^{\prime}\right)+\mathrm{Ce}\left(10^{\prime}\right)$ & -0.56 & 0.78 \\
LT-HTC $\left(20^{\prime}\right)+\mathrm{Ce}\left(15^{\prime}\right)$ & -0.58 & 0.71 \\
\hline
\end{tabular}

that the LT-HTC coating thickness after even 60 minutes is not significant enough to cause appreciable depletion of $\mathrm{Al}$ ions in solution 2. Table 5 shows that incorporation of $\mathrm{Ce}$ in HT-HTC does not alter $\mathrm{E}_{\text {corr }}$ of the specimen but decreases the $i_{\text {corr }}$. This table also shows that increase in duration of Ce treatment has no marked effect on $i_{\text {corr }}$. Table 6 shows that cerium incorporation in the LT-HTC coating from the cerium nitrate bath containing $\mathrm{H}_{2} \mathrm{O}_{2}$ as an accelerator needs to be done for at least 15 minutes to observe decrease of $i_{\text {corr }}$

\subsection{Observations from field tests}

Examination of the coupons after extended exposure to the spent fuel section of the IEA-R1 reactor was done with an optical microscope. The top surface of the untreated coupons revealed more pits compared to the bottom facing surface of the same coupon, indicating the influence of settled solids on the top surfaces. The surface features of the coupons exposed for 3 and 5 months, as compared with those prior to exposure are summarized in Table 7 . The untreated coupons were stained and revealed many pits. After 3 months of exposure the LT-HTC coated coupon revealed no pits but after 5 months, it revealed pits even with post treatments. The HT-HTC coated coupons did not reveal any pits even after 5 months exposure. On the basis of these observations the full-size plates were coated with HT-HTC only.

The plates exposed for 14 months were examined visually and with an optical microscope and the main surface features are summarized in Table 8 . The plates were stained due to formation of thicker surface oxide. The uncoated plates revealed number of pits and the HTC coated plates although stained and dark, did not reveal any pits.

\section{Discussion}

The electrochemical measurements and field tests indicated a marked increase in corrosion resistance of AA 6061 coated with HT-HTC. The corrosion resistance of the alloy was further enhanced by cerium incorporation in the coating. Cerium was chosen to enhance corrosion protection as it is the only rare earth (besides europium) that changes its oxidation state and forms a water insoluble hydroxide/oxide on Al. The faint yellow coating obtained upon immersion of the HTC coated specimen, coupon or plate in the cerium solution is constituted of an insoluble cerium hydroxide/oxide ${ }^{4,15,16}$. Progressive loss of the yellow color with time was observed and this could be attributed 


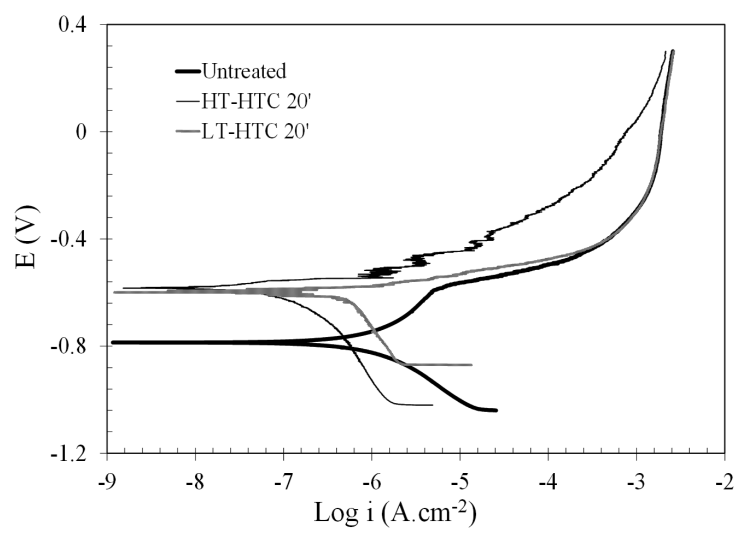

(a)

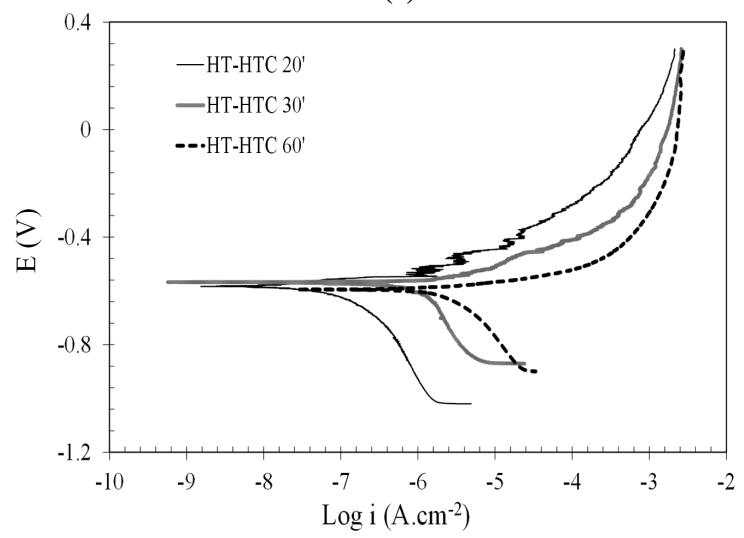

(b)

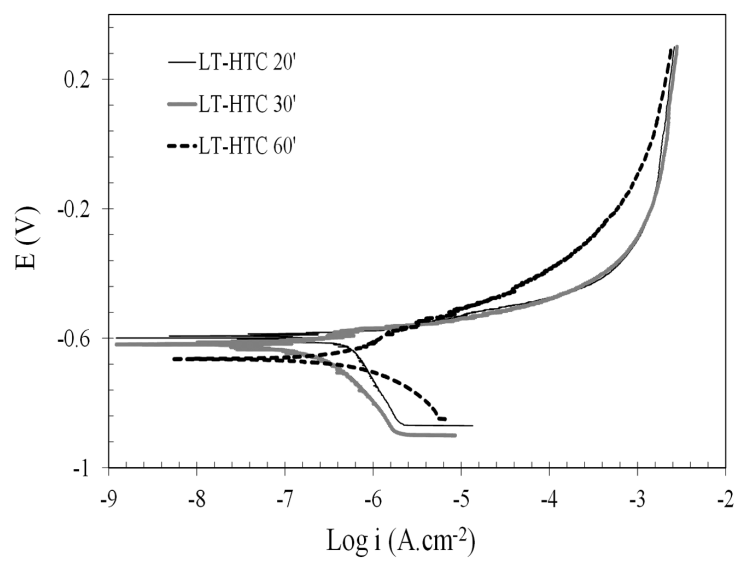

(c)

Figure 5. Polarization curves of uncoated and HTC coated AA 6061 specimens in $0.01 \mathrm{M} \mathrm{NaCl}$. (a) Uncoated, HT-HTC and LT-HTC coated; (b) HT-HTC coated for different duration; (c) LT-HTC coated for different duration.

to the hydroxide transforming to oxide ${ }^{17}$, or degradation of the surface peroxide containing species. The HTC layer imparts pitting corrosion protection by acting as a physical barrier between the aqueous environment and the surface. The higher corrosion resistance of HT-HTC coated specimens compared with LT-HTC coated specimens is due to the former being thicker, both the barrier and the top layer. Further, coarsening of the well-formed HT-HTC crystallites
Table 7. Coupon surface features compared to those observed prior to exposure to the IEA-R1 research reactor spent fuel section.

\begin{tabular}{lcc}
\hline \multirow{2}{*}{ Coating } & \multicolumn{2}{c}{ Surface features after exposure for } \\
\cline { 2 - 3 } & $\mathbf{3}$ months & $\mathbf{5}$ months \\
\hline None & Many pits & Stained + many pits \\
HT-HTC & No difference & No difference \\
HT-HTC + Ce & No difference & No difference \\
LT-HTC & No difference & Dark + some pits \\
LT-HTC + Ce & No difference & Dark + some pits \\
\hline
\end{tabular}

Table 8. Uncoated and coated plate surface features after 14 months exposure to the IEA-R1 reactor's spent fuel section.

\begin{tabular}{ccc}
\hline \multirow{2}{*}{ Coating } & \multicolumn{2}{c}{ Plate surface features } \\
\cline { 2 - 3 } & Side - A & Side - B \\
\hline None & 11 pits, surface dark. & 5 pits, surface dark. \\
HTC & No pits, drying stains. & No pits, drying stains. \\
HTC + Ce & No pits, stained. & No pits, stained. \\
\hline
\end{tabular}

during long term exposure in the spent fuel section, akin to a hydrothermal treatment, increases even more the physical protection given by this coating ${ }^{4}$. The mechanism by which the cerium in the HTC imparts protection is considered to be 'active corrosion protection', analogous to chromium coatings. Basically, this involves release of $\mathrm{Ce}$ ions from the coating, transport of Ce ions through the solution and its action at defect sites to stifle corrosion. It has been speculated that if a $\mathrm{Ce}^{4+}$ bearing inorganic coating contacts a solution, soluble $\mathrm{Ce}^{4+}$ is released into the solution. When these ions encounter reducing conditions, like those associated with exposed bare metal at coating defects, it reduces to $\mathrm{Ce}^{3+}$, which forms an insoluble hydroxide and precipitates. The precipitated cerium hydroxide at the defect then stifles further corrosion ${ }^{3,15}$. Another reason that can be attributed for the increased protection given by the HT-HTC $+\mathrm{Ce}$ compared with that given by LT-HTC $+\mathrm{Ce}$ is the presence of more $\mathrm{Ce}$ in HT-HTC, due mainly to availability of more sites on the HT-HTC surface for cerium to deposit compared to that on the LT-HTC surface.

\section{Conclusions}

1. Hydrotalcite (HTC) coatings on AA 6061 alloy were formed in a nitrate bath at $98{ }^{\circ} \mathrm{C}$ and a carbonate bath at room temperature.

2. HT-HTC coating increased corrosion resistance of the alloy more than the LT-HTC coating.

3. Cerium incorporation in the HT-HTC coating increased further the corrosion resistance of the alloy.

4. The corrosion resistance of HT-HTC coated specimens decreased with increase in duration of HTC formation. 
5. The corrosion resistance of the LT-HTC coated specimens did not vary with increase in duration of HTC formation.

6. Effect of cerium incorporation in the LT-HTC on corrosion resistance of the alloy was evident only after 20 minutes of treatment.

\section{References}

1. International Atomic Energy Agency - IAEA. Corrosion of research reactor aluminium clad spent fuel in water. Vienna; 2003. Technical Report Series, 418.

2. Ramanathan LV, Haddad R, Adelfang P and Ritchie I. Corrosion of spent aluminium-clad research reactor fuel-Synergism in the role of storage basin water parameters. In: Transactions of Research Reactor Fuel Management - RRFM; 2008; Hamburg, Germany. Brussels: European Nuclear Society; 2008. p. 9-13.

3. Harvey TG. Cerium based conversion coatings on aluminium alloys: a process review. Corrosion Engineering, Science and Technology. 2013; 4(48):248-269. http://dx.doi.org/10.1179/1 743278213 Y.0000000089.

4. Buchheit RG, Bode MD and Stoner GE. Corrosion-resistant chromate-free talc coatings for aluminum. Corrosion. 1994; 50(3):205-214. http://dx.doi.org/10.5006/1.3293512.

5. Drewien CA, Eatough MO, Tallant TR, Hills CR and Buchheit RG. Lithium-aluminum-carbonate-hydroxide hydrate coatings on aluminium alloys: composition, structure, and processing bath chemistry. Journal of Materials Research. 1996; 11(6):15071513. http://dx.doi.org/10.1557/JMR.1996.0188.

6. Zhang $\mathrm{W}$ and Buchheit RG. Hydrotalcite coating formation on $\mathrm{Al}-\mathrm{Cu}-\mathrm{Mg}$ alloys from oxidizing bath chemistries. Corrosion. 2002; 58(7):591-600. http://dx.doi.org/10.5006/1.3277650.

7. Hinton BRW, Arnott DR and Ryan NE. Cerium conversion coatings for the corrosion protection of aluminum. Materials Forum. 1986; 9(3):162-172.

8. Arnott DR, Ryan NE, Hinton BRW, Sexton BA and Hughes AE. Auger and XPS studies of cerium corrosion inhibition on 7075 aluminum alloy. Applications of Surface Science. 1985; 22-23:236-251. http://dx.doi.org/10.1016/0378-5963(85)90056-X.

9. Dabalà M, Armelao L, Buchberger A and Calliari I. Ceriumbased conversion layers on aluminum alloys. Applied Surface Science. 2001; 172(3-4):312-322. http://dx.doi.org/10.1016/ S0169-4332(00)00873-4.
7. Coupons and full-size plates coated with HT-HTC and exposed to the IEA-R1 reactor spent fuel section for 14 months did not reveal any pits, indicating marked potential for use of HT-HTC as a protective coating on spent RR fuel during long term wet storage.

10. Hughes AE, Hardin SG, Wittel KW and Miller PR. Surface conversion of aluminum and aluminum alloys for corrosion protection. In: Proceedings of the NACE Meeting: Corrosion/2000, Research Topical Symposium; 2000; Orlando, USA. Houston: NACE International; 2000.

11. Fernandes SMC, Correa OV, Souza JA and Ramanathan LV. A coating to protect spent aluminium-clad research reactor fuel assemblies during extended wet storage. In: Transactions of Research Reactor Fuel Management - RRFM; 2009; Vienna, Austria. Brussels: European Nuclear Society; 2009. p. 60-65.

12. Fernandes SMC, Correa OV, Souza JA and Ramanathan LV. Lanthanide based conversion coatings for long term wet storage of aluminium-clad spent fuel. In: Transactions of Research Reactor Fuel Management - RRFM; 2010; Marrakech, Morocco. Brussels: European Nuclear Society; 2010. p. 111-115.

13. Fernandes SMC, Correa OV, Souza JA, Lima NB, Ramanathan $\mathrm{LV}$, Antunes RA, et al. Conversion coatings to protect aluminiumclad spent fuel in wet storage. In: Transactions of Research Reactor Fuel Management - RRFM; 2013; St. Petersburg, Russia. Brussels: European Nuclear Society; 2013. p. 132-139.

14. Buchheit RG, Mamidipally SB, Schmutz P and Guan H. Active corrosion protection in Ce-modified hydrotalcite conversion coatings. Corrosion. 2002; 58(1):3-14. http://dx.doi. org/10.5006/1.3277303.

15. Arnott DR, Hinton BRW and Ryan NE. Cationic film-forming inhibitors for the corrosion protection of AA 7075 aluminum alloy in chloride solutions. Materials Performance. 1987; 26(8):42-47.

16. Arnott DR, Hinton BRW and Ryan NE. Cationic-film-forming inhibitors for the protection of the AA7075 aluminum alloy against corrosion in aqueous chloride solution. Corrosion. 1989; 45(1):12-18. http://dx.doi.org/10.5006/1.3577880.

17. Scholes FH, Soste C, Hughes AE, Hardin SG and Curtis PR. The role of hydrogen peroxide in the deposition of cerium based conversion coatings. Applied Surface Science. 2006; 253(4):17701780. http://dx.doi.org/10.1016/j.apsusc.2006.03.010. 